\title{
Antilipolytic and lipolytic effects of administering free or ruminally protected nicotinic acid to feed-restricted Holstein cows
}

\author{
J. B. Pescara, ${ }^{*}$ J. A. A. Pires, $\dagger$ and R. R. Grummer*1 \\ ${ }^{*}$ Department of Dairy Science, University of Wisconsin, Madison 53706 \\ †INRA, UR1213 Herbivores, Site de Theix, F-63122 Saint-Genès-Champanelle, France
}

\begin{abstract}
The objectives were to determine effects of 12 hourly infusions of different quantities of nicotinic acid (NA) on plasma nonesterified fatty acid (NEFA; experiment 1) and whether longer $(108 \mathrm{~h})$ continuous infusions of NA could induce sustained reductions of plasma NEFA (experiment 2) in nonlactating, nongestating Holstein cows that were feed restricted. Experiment 1 was a $5 \times 5$ Latin square with 6 -d periods and 9 recovery days between each period. Each period consisted of 5 $\mathrm{d}$ of partial feed restriction to increase plasma NEFA concentration. Treatments were abomasal infusions of $0,0.25,0.5,1$, or $3 \mathrm{mg}$ of $\mathrm{NA} / \mathrm{h}$ per kilogram of body weight (BW), infused as hourly boluses for $12 \mathrm{~h}$, starting $4 \mathrm{~d}$ after initiation of partial feed restriction. Plasma NEFA was decreased for the highest dose: from $448 \mu \mathrm{Eq} / \mathrm{L}$ to $138 \pm 75 \mu \mathrm{Eq} / \mathrm{L}$ at $1 \mathrm{~h}$ after the first bolus of $3 \mathrm{mg}$ of NA/h per kilogram of BW. This initial reduction in plasma NEFA concentration was followed by an increase in concentration at 2,3 , and $4 \mathrm{~h}$ relative to initiation of infusions. Plasma NEFA then decreased to $243 \mu \mathrm{Eq} / \mathrm{L} 6 \mathrm{~h}$ after initiation of treatments and remained low until termination of infusions. A rebound in plasma NEFA concentration occurred at 3 and $4 \mathrm{~h}$ after termination of infusion for cows that received 3 $\mathrm{mg}$ of NA/h per kilogram of BW. Experiment 2 was a $5 \times 5$ Latin square with 7 -d periods and 9 recovery days between each period. Each period consisted of 5 $\mathrm{d}$ of partial feed restriction to increase plasma NEFA concentration. Treatments were continuous abomasal infusion of $0,0.5,1$, or $3 \mathrm{mg}$ of free $\mathrm{NA} / \mathrm{h}$ per kilogram of $\mathrm{BW}$ for $4.5 \mathrm{~d}$ starting at feed restriction or $0.5 \mathrm{mg}$ of NA/h per kilogram of BW infused directly into the rumen in a form protected from microbial degradation. The ruminal administration of protected NA was initiated $2 \mathrm{~d}$ before abomasal infusions and initiation of feed restriction to establish steady postruminal delivery of NA by start of abomasal infusions. Plasma
\end{abstract}

Received May 4, 2010.

Accepted July 8, 2010

${ }^{1}$ Corresponding author: rgrummer@wisc.edu
NEFA was approximately $70 \mu \mathrm{Eq} / \mathrm{L}$ before initiation of feed restriction and increased to $509,587,442,850$, and $108 \mu \mathrm{Eq} / \mathrm{L}$ at $4.5 \mathrm{~d}$ for cows that received $0,0.5$ (protected NA), 0.5 (free NA), 1, and $3 \mathrm{mg}$ of NA/h per kilogram of BW, respectively. An antilipolytic response was achieved with the highest abomasal dose, which maintained plasma NEFA concentration lower than the control group. An increase in plasma NEFA concentration was observed after termination of infusions for cows that received 1 and $3 \mathrm{mg}$ of $\mathrm{NA} / \mathrm{h}$ per kilogram of BW. Plasma NEFA was $1,900 \mu \mathrm{Eq} / \mathrm{L}$ at 4 $\mathrm{h}$ after termination of infusion for cows receiving $1 \mathrm{mg}$ of NA/h per kilogram of BW and 1,360 $\mu \mathrm{Eq} / \mathrm{L}$ at $5 \mathrm{~h}$ after termination of infusion for cows receiving $3 \mathrm{mg}$ of $\mathrm{NA} / \mathrm{h}$ per kilogram of BW. In nongestating, nonlactating cows it is unlikely that a dose of NA exists that will reduce plasma NEFA concentration and prevent the rebound that occurs following termination of NA administration.

Key words: nicotinic acid, nonesterified fatty acid, bovine

\section{INTRODUCTION}

The most challenging period of the production cycle for a dairy cow is the transition period, defined as 3 wk prepartum until 3 wk postpartum. During this time frame, metabolism of the pregnant or lactating cow is altered to accommodate the nutrient demands required to support conceptus growth and initiation of milk production (Bauman and Currie, 1980; Grummer, 1993).

Negative energy balance is observed in transition cows because of the increase in energy requirements and a depression in energy intake during late pregnancy and early lactation. An increase in plasma NEFA concentration is commonly observed to support energy requirements for milk synthesis and provide precursors for milk fat synthesis. However, exaggerated plasma NEFA concentration leads to triacylglycerol accumulation in the liver and ketosis (Grummer, 1993; Vazquez-Añon et al., 1994). Large doses of NA reduced NEFA release from adipose tissue, leading to lowered ketone body formation (Waterman and Schultz, 1973). Furthermore, 
a transient decrease in NEFA concentration followed by a rebound was observed in dairy cows when oral nicotinic acid (NA) boluses were administered (Waterman and Schultz, 1972; Waterman et al., 1972; Jaster et al., 1983). However, ruminant animals were unresponsive to NA when lower doses were fed. For example, plasma NEFA concentration was reduced in only 1 out 11 studies when lower doses of free niacin were supplemented to dairy cows (NRC, 2001). A meta-analysis from 27 studies reported no effects on efficacy for DMI, milk yield, plasma NEFA, BHBA, and glucose concentrations when $6 \mathrm{~g} / \mathrm{d}$ of NA was supplemented, but FCM and milk protein yield increased when $12 \mathrm{~g} / \mathrm{d}$ were fed (Schwab et al. 2005). This lack of effects may be explained by extensive degradation of NA in the rumen (Zinn et al., 1987; Campbell et al., 1994).

In an attempt to identify the amount of postruminal NA required to elicit an antilipolytic response, Pires and Grummer (2007) infused various amounts of NA into the abomasum of feed-restricted Holstein cows. The minimum dose administered (6 $\mathrm{mg}$ of $\mathrm{NA} / \mathrm{kg}$ of $\mathrm{BW}$ ) appeared to elicit maximum inhibition of lipolysis. Additionally, for all doses tested, termination of infusion was followed by a rebound in plasma NEFA concentrations. Therefore, 2 experiments were conducted to determine the effects of lower rates of NA infusion on plasma NEFA concentrations during negative energy balance induced by partial feed restriction. We hypothesized that a dose of NA exists that suppresses plasma NEFA and prevents the previously observed rebound following termination of treatment.

\section{MATERIALS AND METHODS}

\section{Experimental Design Common to Experiment 1 and Experiment 2}

In each experiment, 5 nonlactating, nongestating, ruminally cannulated Holstein cows were used in a $5 \times$ 5 Latin square design. All cows had completed at least 2 lactations. Cows were rumen cannulated to allow infusion of treatments into the abomasum and prevent ruminal degradation of NA (Gressley et al., 2006). Nicotinic acid (99.7\% purity; Balchem Corp., New Hampton, NY) was diluted in water with equimolar amounts of sodium bicarbonate to facilitate solubilization. Nine days were allowed between each experimental period to reduce the likelihood of carryover effects.

Starting at least 2 wk before initiation of treatments, cows were allowed to consume ad libitum a TMR composed of $34 \%$ alfalfa silage, $54 \%$ corn silage, $8 \%$ straw, and $4 \%$ wheat middlings as the carrier for vitamin and minerals (DM basis) at a rate to meet or exceed NRC
(2001) recommendations. Based on NRC (2001) feed composition values, the diet was formulated to have $46 \% \mathrm{NDF}, 30 \% \mathrm{ADF}, 12 \% \mathrm{CP}$, and $1.32 \mathrm{Mcal}$ of $\mathrm{NE}_{\mathrm{L}^{-}}$ $3 \times / \mathrm{kg}$. Animals were allowed free access to water.

Cows were weighed 6 to $7 \mathrm{~h}$ after the daily allotment of feed was offered, each period, on 2 consecutive days before initiation of treatments. Body weight was used to determine maintenance nutrient requirements and doses of NA. Each experimental period, mobilization of body reserves and increase in plasma NEFA concentration were stimulated by partial feed restriction. During feed restriction, cows were offered an amount of TMR corresponding to $30 \%$ of energy requirements (NRC, 2001). A block of trace mineralized salt was available for each cow during each period.

The estrous cycle was controlled during both trials using intravaginal progesterone releasing devices containing $1.38 \mathrm{~g}$ of progesterone (Easi-Breed, Hamilton, $\mathrm{NZ}$ ). The device was reinserted every $7 \mathrm{~d}$ to maintain a high and constant progesterone concentration and inhibit ovulation during the experiment. Doing so decreased potential interference of fluctuating reproductive hormones on blood metabolite concentrations.

Daily blood samples were collected by venipuncture from the coccygeal vein or artery using Vacutainer tubes (Becton Dickinson, Franklin Lakes, NJ). On the day before hourly blood withdrawal, catheters (polyurethane 14-gauge $\times 13 \mathrm{~cm}$; MILA International Inc., Erlanger, KY) were fitted into the jugular vein of each cow and attached to an extension set $(86 \mathrm{~cm}, 3.9 \mathrm{~mL}$ volume; Baxter International Inc., Deerfield, IL). Patency was maintained by flushing the catheter with 8 $\mathrm{mL}$ of heparinized saline $(100 \mathrm{IU} / \mathrm{mL})$ after catheter placement or with diluted heparinized saline (10 IU/ $\mathrm{mL}$ ) during sampling. Blood was drawn from the catheters into disposable 20-mL syringes and immediately transferred to Vacutainer tubes (Becton Dickinson). Tubes for collection of blood (6 mL; containing $12 \mathrm{mg}$ of potassium oxalate and $15 \mathrm{mg}$ of sodium fluoride as a glycolytic inhibitor) were kept on ice until centrifugation at $920 \times g$ at $4^{\circ} \mathrm{C}$ for 20 min to obtain plasma.

\section{Experimental Design Unique to Experiment 1}

Each experimental period, cows were partially feed restricted for $6 \mathrm{~d}$. During the first $4 \mathrm{~d}$ of partial feed restriction, feed was offered once daily at $0600 \mathrm{~h}$; however, on d 5, the daily feed allotment was divided into 24 equal doses and administered hourly via ruminal cannula. Administration of treatments started on d 5 of partial feed restriction and consisted of 12 consecutive hourly abomasal infusions of water $(1 \mathrm{~L})$ or the same volume of water providing a dose of $0.25,0.5,1$, and 3 
mg of NA/h per kilogram of BW. Each hourly dose was infused over approximately 2 min and was preceded by the collection of a blood sample.

During d 1 to 4 of partial feed restriction, blood was drawn once daily immediately before morning feeding by venipuncture from the coccygeal vein or artery. On d 5, blood samples were collected each hour starting immediately before first treatment administration and continuing for $24 \mathrm{~h}$ thereafter. Plasma samples were analyzed for NEFA, glucose, and insulin. However, to reduce cost of analysis, insulin and BHBA were analyzed only for samples obtained at chosen time points from cows that received 0,1 , and $3 \mathrm{mg}$ of $\mathrm{NA} / \mathrm{h}$ per kilogram of BW.

\section{Experimental Design Unique to Experiment 2}

Each experimental period lasted $7 \mathrm{~d}$; cows were fed ad libitum on d 1 and 2 and were partially feed restricted on d 3 to 7 . Individual daily feed allotment was divided into equal doses and each dose was offered every $6 \mathrm{~h}$. Treatments were either continuous abomasal infusion of water or free NA or ruminal administration of rumen-protected NA (NiaShure, Balchem Corp.). Abomasal infusions of free NA or water started on d 3 , which corresponds to the beginning of partial feed restriction. Abomasal infusions were performed continuously for 4.5 d. Free NA was administered at a rate of $0.5,1.0$, and $3.0 \mathrm{mg}$ of $\mathrm{NA} / \mathrm{h}$ per kilogram of BW. Abomasal infusions were administered using a dual syringe pump (model 33, Harvard Apparatus Inc., Holliston, MA). Water and NA solutions were infused at a rate of $200 \mathrm{~mL} / \mathrm{h}$. In contrast, ruminal administration of rumen-protected NA started $2 \mathrm{~d}$ before the beginning of feed restriction (d 1 and 2 of each period). The rumen-protected NA treatment lasted $6.5 \mathrm{~d}$, and the boluses were administered every $6 \mathrm{~h}$ through the rumen cannula, immediately before feed was offered. Protected NA was administered at a rate corresponding to $0.5 \mathrm{mg}$ of $\mathrm{NA} / \mathrm{h}$ per kilogram of $\mathrm{BW}$.

For $2 \mathrm{~d}$ before initiation of feed restriction, daily blood samples were collected at $0600 \mathrm{~h}$, immediately before the morning feeding, by puncture from the coccygeal vein or artery. One day before feed restriction, a 14-gauge catheter was placed into the jugular vein to facilitate more frequent blood sampling. Samples were collected every $6 \mathrm{~h}$ before feeding during d 3 to 6.5 of each period. After termination of infusions, blood samples were collected hourly for an additional $12 \mathrm{~h}$. Samples were analyzed for plasma NEFA concentration.

\section{Blood Plasma and Serum Analysis}

Plasma was analyzed for NEFA (acetyl-CoA synthase, acyl-CoA oxidase and peroxidase, HR Series NEFA - 2; Wako Pure Chemical Industries Ltd. USA, Richmond, VA), BHBA (Gibbard and Watkins, 1968), and glucose (glucose oxidase-peroxidase method; Karkalas, 1985). The NEFA assay was conducted according to kit instructions except the volume for plasma samples; standards and blank was doubled $(10 \mu \mathrm{L})$. Serum was analyzed for insulin using a porcine RIA kit (Linco Research Inc., St. Charles, MO).

\section{Statistical Analysis}

Data were analyzed using the MIXED procedure of SAS version 9.1 (SAS Institute, 2004) using KenwardRogers adjustment for calculation of denominator degrees of freedom and either first-order autoregressive covariance structure or heterogeneous first-order autoregressive covariance structure, depending on which provided the best fit according to the Schwarz's Bayesian criterion. Spatial power covariance structure was used whenever needed to allow for unequal spacing between sampling times.

Data from the preinfusion, infusion, and postinfusion periods were analyzed separately. The statistical model for both experiments included the fixed effects of treatment, time, and treatment by time interaction and the random effects of period and cow. Treatment by time interaction was removed from the model if not significant $(P>0.05)$.

Body weight and BCS were analyzed across all periods using a model that included cows as random effect and period as fixed effect. Body weight and BCS data were analyzed primarily to determine whether there were period effects on these variables.

To comply with the assumptions of normality and variance homogeneity of residuals, logarithmic transformation was used for the statistical analysis of plasma NEFA, insulin, and glucose. Least squares means and standard errors of the mean reflect untransformed data, and $P$-values reflect statistical analysis of transformed data.

In both experiments, the PDIFF option of SAS was used to compare treatments when treatment effect was significant. The SLICE option of SAS was used to compare treatment differences at individual time points when treatment by time interaction was significant. The significance level was predefined at $P \leq 0.05$, and trends toward significance were considered at $0.05<P \leq 0.10$. 


\section{RESULTS AND DISCUSSION}

\section{Experiment 1}

Body weight $(781 \pm 30 \mathrm{~kg})$ and BCS $(3.4 \pm 0.2$; mean \pm SD) were not affected by period. This indicates that feed restriction was not too severe, or that sufficient recovery time was allowed for weight gain between periods, or both.

Plasma NEFA concentration increased $(P<0.001)$ from $104 \mu \mathrm{Eq} / \mathrm{L}$ on d 0 to $467 \mu \mathrm{Eq} / \mathrm{L}$ on $\mathrm{d} 4$ of feed restriction (Figure 1). A similar pattern was observed in previous studies when nonlactating, nongestating Holstein cows were submitted to total feed restriction for 48 h. Plasma NEFA concentration increased $(P<$ 0.001 ) from 198 to $546 \mu \mathrm{Eq} / \mathrm{L}$ (Pires and Grummer, 2007) and from 134 to $545 \mu \mathrm{Eq} / \mathrm{L}$ (Pires et al., 2007).

Abomasal infusion of NA induced significant treatment, time, and treatment by time effects on plasma NEFA concentration (Figure 2). Plasma NEFA concentration during the $12 \mathrm{~h}$ of infusions were 464, 476, 474, 442 , and $284 \mu \mathrm{Eq} / \mathrm{L}$ for $0,0.25,0.5,1$, and $3 \mathrm{mg}$ of $\mathrm{NA} / \mathrm{h}$ per kilogram of BW, respectively. The highest NA infusion rate was the only rate to decrease plasma NEFA $(P<0.01)$, which indicates that $0.25,0.5$, or 1 mg of NA/h per kilogram of BW was not sufficient to attenuate body lipid mobilization. Plasma NEFA was reduced from $448 \mu \mathrm{Eq} / \mathrm{L}$ at time 0 (which corresponds to $4 \mathrm{~d}$ of feed restriction) to $138 \pm 75 \mu \mathrm{Eq} / \mathrm{L}$ at $1 \mathrm{~h}$ after the first bolus of $3 \mathrm{mg}$ of $\mathrm{NA} / \mathrm{h}$ per kilogram of BW (Figure 2). This reduction in plasma NEFA concentration was followed by a temporary rebound in concentration during h 2,3 , and 4 (treatment $\times$ time effect; $P<0.001$; Figure 2). This rebound in plasma NEFA concentration indicates that a single dose of 3 mg of NA/kg of BW may not be sufficient to sustain reduced plasma NEFA concentration, possibly because of rapid clearance of NA from the blood (Pires et

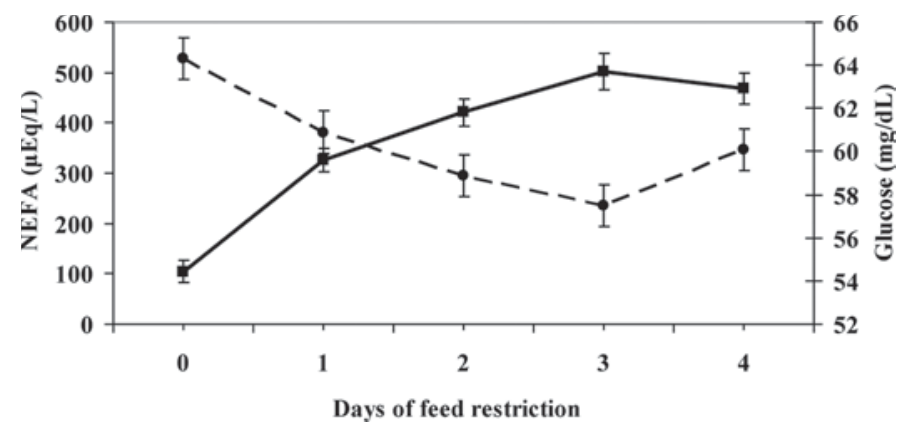

Figure 1. Experiment 1: plasma NEFA (ם, solid line) and glucose ( , dashed line) concentrations when feed was restricted to $30 \%$ of energy requirements. Feed restriction started on $\mathrm{d} 0$ and continued for 96 h (d 4). Significant effect: day $(P<0.001)$. al., 2008). However, $6 \mathrm{~h}$ after initiation of treatment, plasma NEFA concentration decreased to $243 \mu \mathrm{Eq} / \mathrm{L}$ and remained depressed until termination of infusions. This eventual reduction of plasma NEFA concentration suggests that continuous infusion of $3 \mathrm{mg}$ of NA/h per kilogram of $\mathrm{BW}$ results in sufficient accumulation of NA in blood to cause a sustained reduction in plasma NEFA concentration, as previously observed during hourly infusions of 6 or $10 \mathrm{mg}$ of NA/h per kilogram of BW (Pires et al., 2008).

The choice of NA infusion rates for this study was based on amounts used in previous studies (Pires and Grummer, 2007; Pires et al., 2007) where single or hourly boluses of NA were administered into the abomasum of nonlactating, nongestating Holstein cows that had been completely feed restricted for $2 \mathrm{~d}$. In the first study, single boluses of NA were infused abomasally at a rate of 6,30 , or $60 \mathrm{mg}$ of $\mathrm{NA} / \mathrm{kg}$ of $\mathrm{BW}$, leading to an initial pattern of plasma NEFA decrease that was similar for all NA treatments. This suggested that all the doses were sufficient to transiently inhibit lipolysis. In a second experiment, abomasal infusion of NA boluses at a rate of 10 or $6 \mathrm{mg}$ of NA/h per kilogram of BW for $9 \mathrm{~h}$ caused a similar reduction in plasma NEFA concentration, which suggests that a maximum antilipolytic response was achieved at $6 \mathrm{mg}$ of NA/h per kilogram of BW.

After termination of NA infusions, significant treatment, time, and treatment by time effects were observed (Figure 3). During the $12 \mathrm{~h}$ following termination of infusions, plasma NEFA concentrations were 399, 404, 405, 407, and $743 \pm 69 \mu \mathrm{Eq} / \mathrm{L}$ for $0,0.25,0.5,1$, and 3 $\mathrm{mg}$ of $\mathrm{NA} / \mathrm{kg}$ of BW per hour, respectively (treatment effect: $P<0.001$; Figure 3). A posttreatment rebound was found in plasma NEFA for the highest NA dose $(P<0.001 ;$ Figure 3). Plasma NEFA concentration reached approximately $1,400 \mu \mathrm{Eq} / \mathrm{L}$ in samples collected at 3 and $4 \mathrm{~h}$ after termination of infusion for cows receiving $3 \mathrm{mg}$ of $\mathrm{NA} / \mathrm{h}$ per kilogram of $\mathrm{BW}$. A mechanism to explain the rebound is unknown, but a similar pattern has been observed in other animal models (Nye and Buchanan, 1969; Waterman and Schultz, 1972; Jaster et al., 1983). The rebound effect is attributed to increased net lipolysis from adipose tissue and not from decreased utilization of circulating fatty acids, as assessed by ${ }^{14} \mathrm{C}$-palmitate metabolism in goats treated with NA (Waterman and Schultz, 1973) and by increased plasma glycerol during the rebound period in sheep and humans (Nye and Buchanan, 1969).

Interestingly, the only dose that showed a rebound effect was the dose causing a decrease in plasma NEFA concentration. Similarly, in a previous experiment (Pires and Grummer, 2007) the 2 highest NA doses infused caused the longest decrease in plasma NEFA 


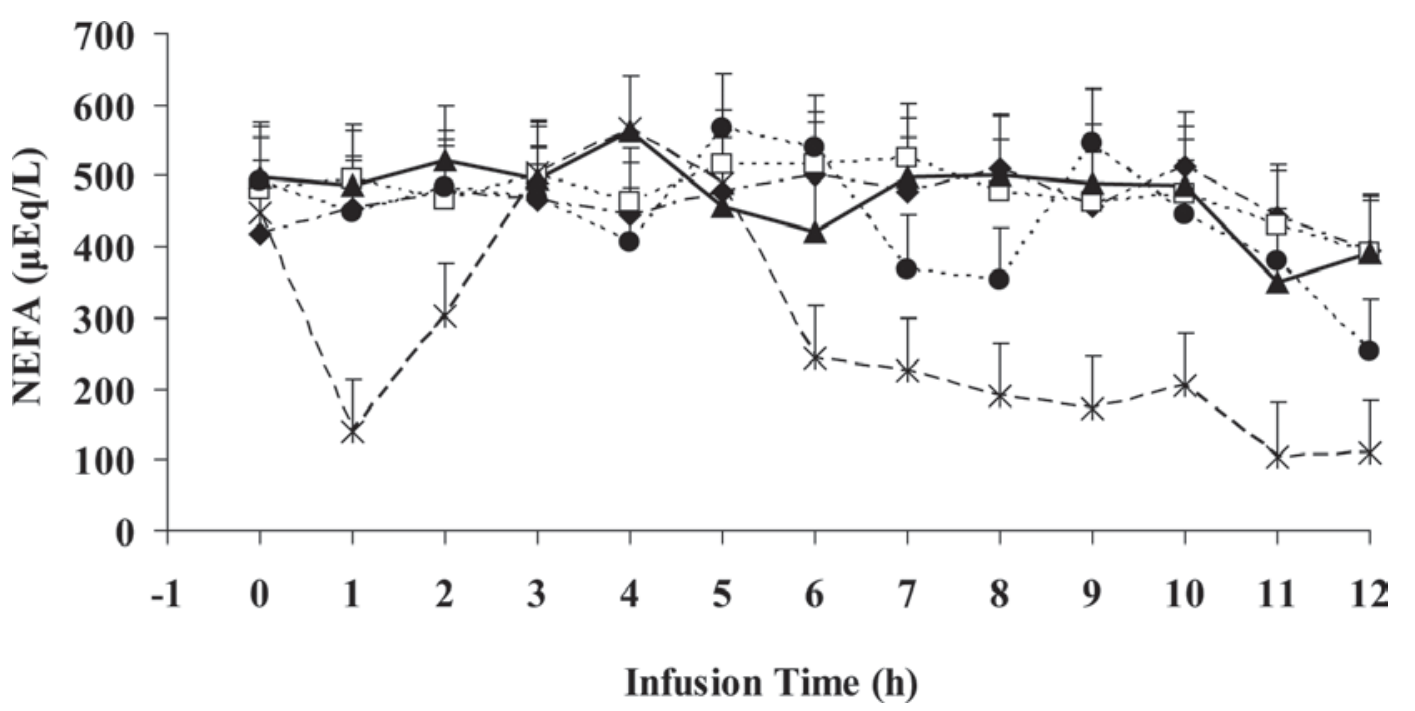

Figure 2. Experiment 1: plasma NEFA concentration during abomasal infusions of nicotinic acid at a rate of 0 ( $\bullet$, dashed-dotted line), 0.25 ( $\square$, dotted line), 0.5 ( $\mathbf{\Lambda}$, solid line), $1.0(\bullet$, dotted line), or $3.0(\times$, dashed line) $\mathrm{mg} / \mathrm{h}$ per kilogram of BW. Hourly doses started at $96 \mathrm{~h}$ of feed restriction (time 0$)$ and were repeated for 12 consecutive hours. Significant effects: treatment $(P<0.001)$, time $(P<0.001)$, and treatment $\times$ time $(P<0.01)$.

concentration but also caused the largest rebound. This suggests that the magnitude of rebound depends on the dose of NA administered. For NA to be an effective agent in lowering plasma NEFA and have potential for preventing or treating ketosis, it would be desirable to identify a rate of administration that would decrease plasma NEFA without a rebound effect. Clearly, when providing hourly doses, this rate was not identified in this experiment. Such a rate may not exist, and if it does, it is within a very small range (i.e., 1 to $3 \mathrm{mg}$ of $\mathrm{NA} / \mathrm{h}$ per kilogram of BW).
A time effect $(P<0.001)$ was observed on plasma glucose concentration during the $4 \mathrm{~d}$ of feed restriction (Figure 1). Glucose concentration decreased $(P<$ 0.001 ) from $64.3 \mathrm{mg} / \mathrm{dL}$ on d 0 to $57.5 \mathrm{mg} / \mathrm{dL}$ on $\mathrm{d} 3$, but then increased $(P<0.001)$ to $60.1 \mathrm{mg} / \mathrm{dL}$ during the last $24 \mathrm{~h}(\mathrm{~d} 4)$. The increase in glucose concentration that followed an initial decline may be attributed to homeostatic regulation to maintain constant blood glucose.

A significant treatment and time effect was found on glucose concentration during administration of treat-

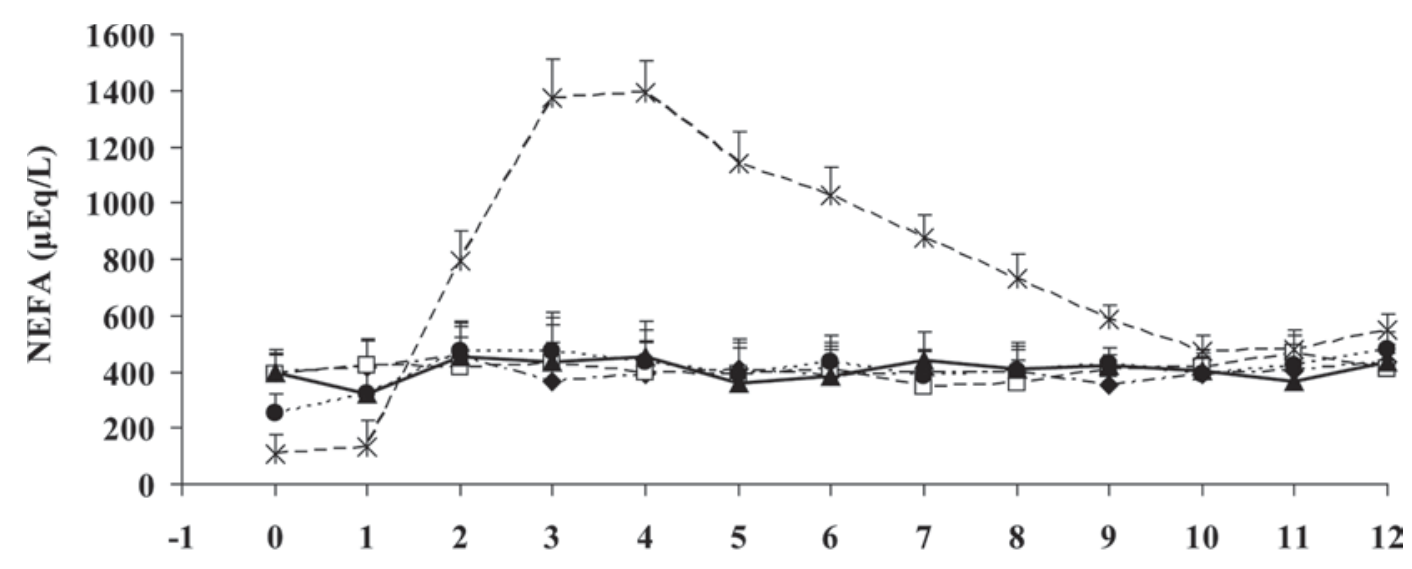

Time after termination of infusions (h)

Figure 3. Experiment 1: plasma NEFA concentration after termination of nicotinic acid infusion at a rate of 0 ( $\bullet$, dashed-dotted line), 0.25 ( $\square$, dashed line), $0.5(\boldsymbol{\Lambda}$, solid line), $1.0(\bullet$, dotted line), or $3.0(\times$, dashed line $) \mathrm{mg} / \mathrm{h}$ per kilogram of BW. Significant effects: treatment $(P<$ $0.01)$, time $(P<0.001)$, and treatment $\times$ time $(P<0.001)$. 


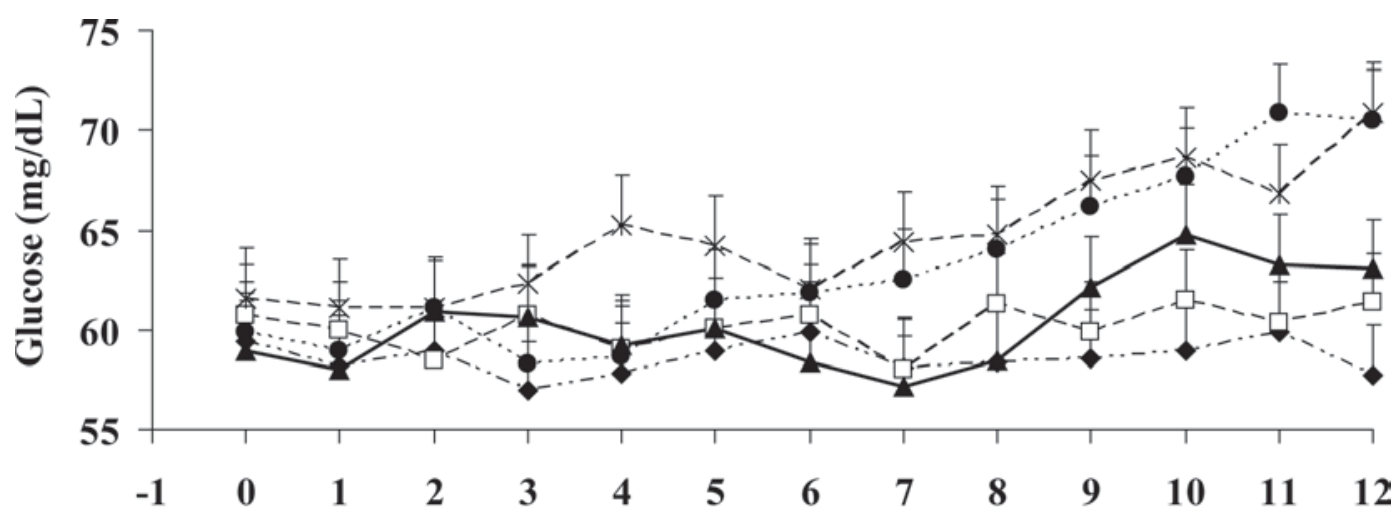

Infusion time (h)

Figure 4. Experiment 1: glucose concentration during abomasal infusions of nicotinic acid at a rate of 0 ( $\bullet$, dashed-dotted line), 0.25 ( $\square$, dashed line), 0.5 ( $\mathbf{\Lambda}$, solid line), $1.0(\bullet$, dotted line), or $3.0(\times$, dashed line) $\mathrm{mg} / \mathrm{h}$ per kilogram of BW. Hourly doses started at $96 \mathrm{~h}$ of feed restriction (time 0$)$ and were repeated for 12 consecutive hours. Significant effects: treatment $(P<0.001)$ and time $(P<0.001)$.

ments (Figure 4). Glucose concentration was greater $(P$ $<0.05)$ when cows were infused at a rate of 1 and $3 \mathrm{mg}$ of NA/h per kilogram of BW compared with $0,0.25$, or $0.5 \mathrm{mg}$ of $\mathrm{NA} / \mathrm{h}$ per kilogram of BW, and the effect appeared to increase with time. However, no treatment by time interaction was observed $(P=0.40$; Figures 4 and $5)$. Plasma glucose concentrations over the duration of infusion were $58.4,60.1,60.4,64.4$, and $64.7 \pm 1.9 \mathrm{mg} /$ $\mathrm{dL}$ for $0,0.25,0.5,1$, and $3 \mathrm{mg}$ of $\mathrm{NA} / \mathrm{h}$ per kilogram of $\mathrm{BW}$, respectively, suggesting that the increase in the rate of NA infused caused an increase in the plasma glucose concentration. In contrast to the present study, no treatment effect was found on plasma glucose concentration during hourly abomasal infusions of 0,6 , or $10 \mathrm{mg}$ of NA/h per kilogram of BW in feed-restricted Holstein cows, but only 2 cows were used per treatment (Pires and Grummer, 2007). Accordingly, abomasal infusion of $6 \mathrm{mg}$ of NA/h per kilogram of BW did not increase plasma glucose compared with control (Pires et al., 2007). In the later study, a trend was found only for treatment by time interaction because of a transient decrease in glucose observed $1 \mathrm{~h}$ after infusion of first NA bolus (Pires et al., 2007). In contrast to previously cited short-term studies, a 3-d continuous infusion of $3 \mathrm{mg}$ of NA/h per kilogram of BW to partially feed restricted lactating dairy cows lead to significant increases in plasma glucose at $72 \mathrm{~h}$ and in serum insulin at 48 and $72 \mathrm{~h}$ of infusion compared with a control (Pires et al., 2009).

Similar patterns were observed by Thornton and Schultz (1980): the dose of niacin administered was positively related to plasma glucose concentration during d 2 and 3 after niacin administration. Pires and Grummer (2007) also demonstrated a trend $(P=$ 0.09 ) for a treatment effect and a treatment by time interaction $(P<0.001)$ after $48 \mathrm{~h}$ of feed restriction in nonlactating Holstein cows. They observed an increase in glucose concentration for the $12 \mathrm{~h}$ that followed abomasal infusion of a single bolus of NA at a rate of 6,30 , or $60 \mathrm{mg} / \mathrm{kg}$ of BW.

The mechanism by which NA increased plasma glucose concentration is unknown; it may involve an increase in hepatic glucose production, a decrease in glucose clearance from blood, or both. Short-term (up to $11 \mathrm{~h}$ ) supplementation of NA to suppress plasma NEFA in partially feed-restricted dry cows enhanced whole-body response to insulin as assessed by glucose tolerance tests (Pires et al., 2007). In contrast, 3-d administration of NA to partially feed-restricted lactating cows at the same rate as in the current experiment (3 $\mathrm{mg}$ of NA/h per kilogram of BW) induced patterns of glucose and insulin concentration during infusion, glucose tolerance tests, and $\beta$-agonist challenges that

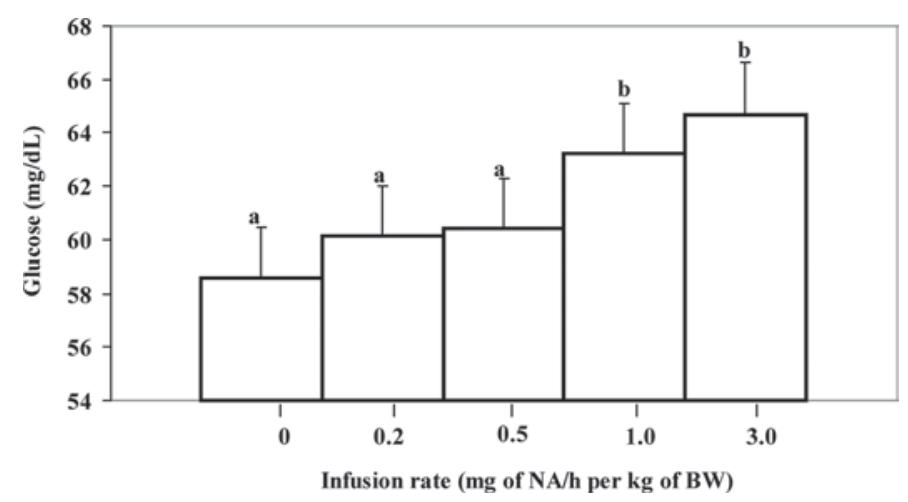

Figure 5. Experiment 1: plasma glucose concentration during abomasal infusions of nicotinic acid (NA) at various rates in feed-restricted Holstein cows. Significant effect: treatment $(P<0.001)$. Bars with different letters are significantly different $(P<0.05)$. 


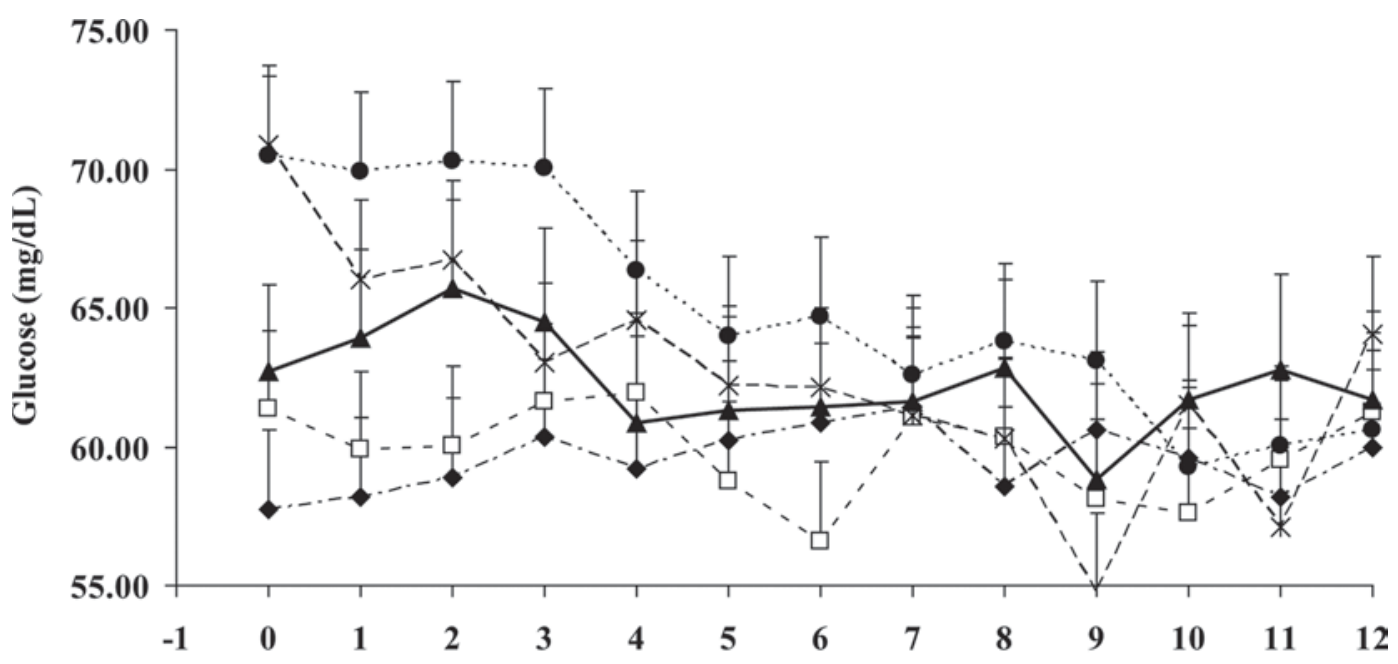

Time after termination of infusion (h)

Figure 6. Experiment 1: plasma glucose concentration after termination of nicotinic acid infusion at a rate of 0 ( $\bullet$, dashed-dotted line), 0.25 ( $\square$, dashed line), $0.5(\boldsymbol{\Lambda}$, solid line), $1.0(\bullet$, dotted line), or $3.0(\times$, dashed line) $\mathrm{mg} / \mathrm{h}$ per kilogram of BW. Significant effects: treatment $(P<$ $0.001)$ and treatment $\times$ time $(P=0.03)$.

indicated the onset of an insulin resistant state (Pires et al., 2009).

After termination of infusions, treatment $(P<0.001)$ and treatment by time $(P=0.03)$ effects were found for plasma glucose concentrations (Figure 6), but no time effect $(P=0.18)$ was found. Plasma glucose concentration during the 12 -h postinfusion period was 59.5, 59.8, $63.3,65.0$, and $62.6 \pm 1.8 \mathrm{mg} / \mathrm{dL}$ for cows receiving 0 , $0.25,0.5,1$, and $3 \mathrm{mg}$ of $\mathrm{NA} / \mathrm{h}$ per kilogram of $\mathrm{BW}$, respectively. Treatment differences in plasma glucose appeared to be attenuated with time postinfusion, suggesting that the clearance of NA from blood may have directly or indirectly reduced its ability to affect glucose concentration. By $19 \mathrm{~h}$ after termination of infusion, no significant differences were found among doses.

A time effect $(P=0.02)$ was found on plasma insulin concentration (Figure 7$)$, but treatment $(P=0.12)$ and treatment by time $(P=0.18)$ effects were not significant during infusions. Interpretation of insulin concentrations requires caution. Only samples corresponding to 0,1 , and $3 \mathrm{mg}$ of $\mathrm{NA} / \mathrm{h}$ per kilogram of $\mathrm{BW}$ treatments were analyzed. Therefore, cells were missing in the Latin square and precision of the estimates was reduced. Plasma insulin concentration followed a response pattern similar to plasma glucose concentration during NA infusion. Data reported by Thornton and Schultz (1980) and Pires and Grummer (2007) suggest that NA is responsible for increased glucose and insulin concentrations. Whether it is a direct effect of NA or an indirect effect mediated by changes in plasma glucose or NEFA is not known.
After termination of infusions, a treatment effect $(P$ $<0.01$ ) was found on plasma insulin concentration; however, no time $(P=0.50)$ or treatment by time $(P$ $=0.13$ ) effects were found (Figure 8). Plasma insulin concentration during the 12 -h postinfusion period was $20.4,38.2$, and $56.4 \pm 18.8 \mu \mathrm{IU} / \mathrm{mL}$ for cows receiving 0,1 , and $3 \mathrm{mg}$ of $\mathrm{NA} / \mathrm{h}$ per kilogram of $\mathrm{BW}$, respectively. After termination of NA infusion, insulin concentration continually decreased for cows receiving $1 \mathrm{mg}$ of $\mathrm{NA} / \mathrm{h}$ per kilogram of BW. However, cows receiving $3 \mathrm{mg}$ of $\mathrm{NA} / \mathrm{h}$ per kilogram of $\mathrm{BW}$ showed an increase in insulin concentration $4 \mathrm{~h}$ after termination of infusion, followed by a decrease that mirrored the rebound in plasma NEFA. Previous studies reported a rebound followed by a decrease in insulin concentration that peaked at $8 \mathrm{~h}$ after a single bolus of NA infusion (Pires and Grummer, 2007). Insulin concentration was higher for cows receiving a single bolus of 60 or 30 compared with $6 \mathrm{mg}$ of $\mathrm{NA} / \mathrm{kg}$ of BW, suggesting that the concentration of insulin in blood may be dependent on NA dose.

$\beta$-Hydroxybutyrate concentrations were measured only for cows receiving the control and 2 highest doses of NA. Plasma BHBA during infusions was 8.4, 6.9, and $5.2 \pm 1.1 \mathrm{mg} / \mathrm{dL}$ for cows receiving 0,1 , and $3 \mathrm{mg}$ of NA/h per kilogram of $\mathrm{BW}$, respectively. A treatment effect $(P=0.01)$ was found on BHBA concentration that was accounted for by the highest dose $(3 \mathrm{mg}$ of NA/h per kilogram of BW; $P<0.05)$. No time $(P$ $=0.13)$ or treatment by time $(P=0.90)$ effects were observed. After termination of infusions, time $(P<$ 


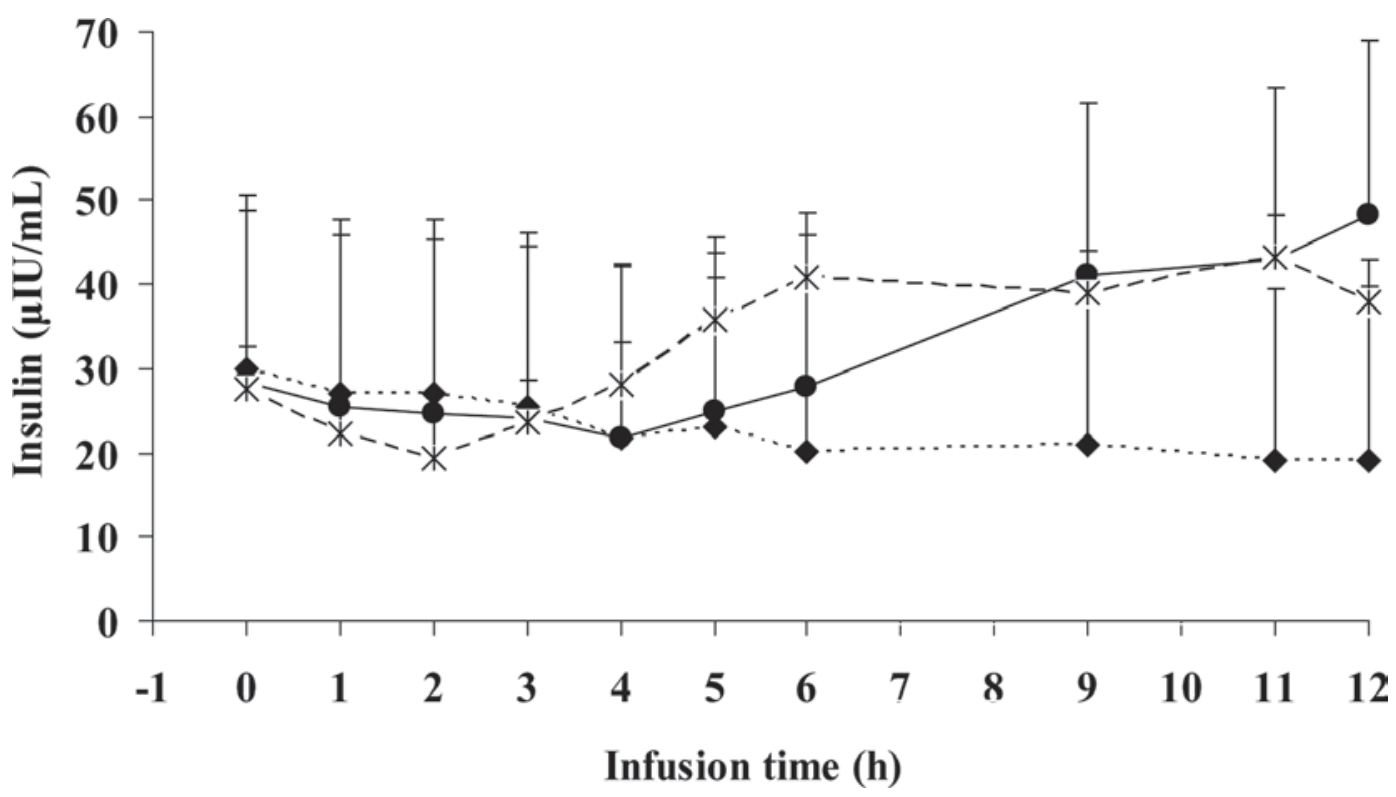

Figure 7. Experiment 1: plasma insulin concentration during abomasal infusions of nicotinic acid at a rate of 0 ( $\bullet$, dotted line), 1.0 ( solid line), or $3.0(\times$, dashed line $) \mathrm{mg} / \mathrm{h}$ per kilogram of BW. Hourly doses started at $96 \mathrm{~h}$ of feed restriction (time 0$)$ and were repeated for 12 consecutive hours. Significant effect: time $(P=0.02)$.

$0.001)$ and treatment by time $(P=0.01)$ effects were observed for plasma BHBA concentration (Figure 9). Plasma BHBA concentration mirrored plasma NEFA concentrations during and after termination of infusions, which is expected because fatty acids are partially oxidized to BHBA during periods of extensive hepatic uptake of NEFA, and it is in agreement with previous research assessing palmitate metabolism using ${ }^{14} \mathrm{C}$ tracer after administration NA boluses to goats (Waterman and Schultz. 1973). Nonetheless, a metaanalysis indicated that feeding 6 or $12 \mathrm{~g}$ of free NA/d did not affect plasma BHBA (Schwab et al., 2005).

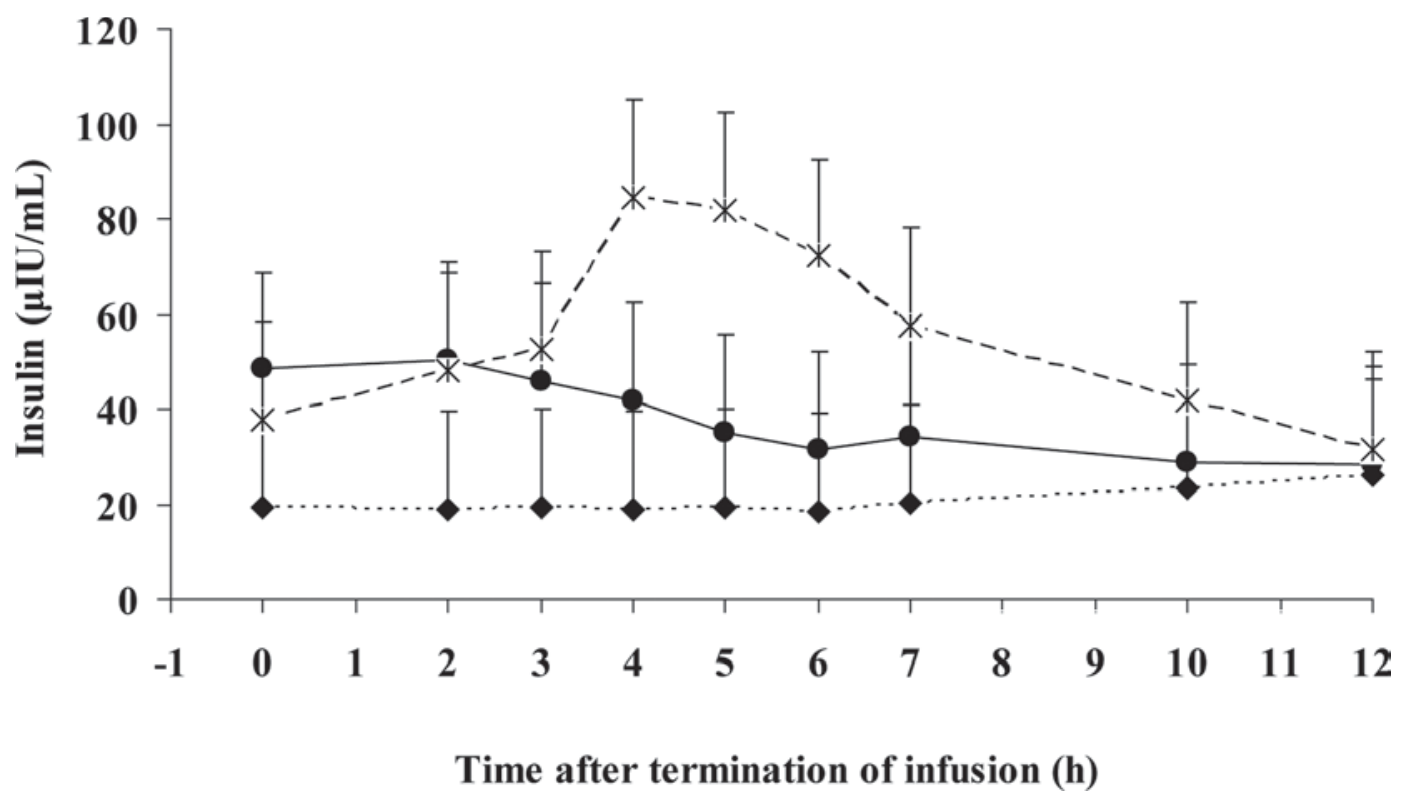

Figure 8. Experiment 1: plasma insulin concentration after termination of nicotinic acid infusion at a rate of $0(\bullet$, dotted line), $1.0(\bullet$, solid line), or $3.0(\times$, dashed line $) \mathrm{mg} / \mathrm{h}$ per kilogram of BW. Significant effects: treatment $(P<0.01)$ and time $(P=0.51)$. 


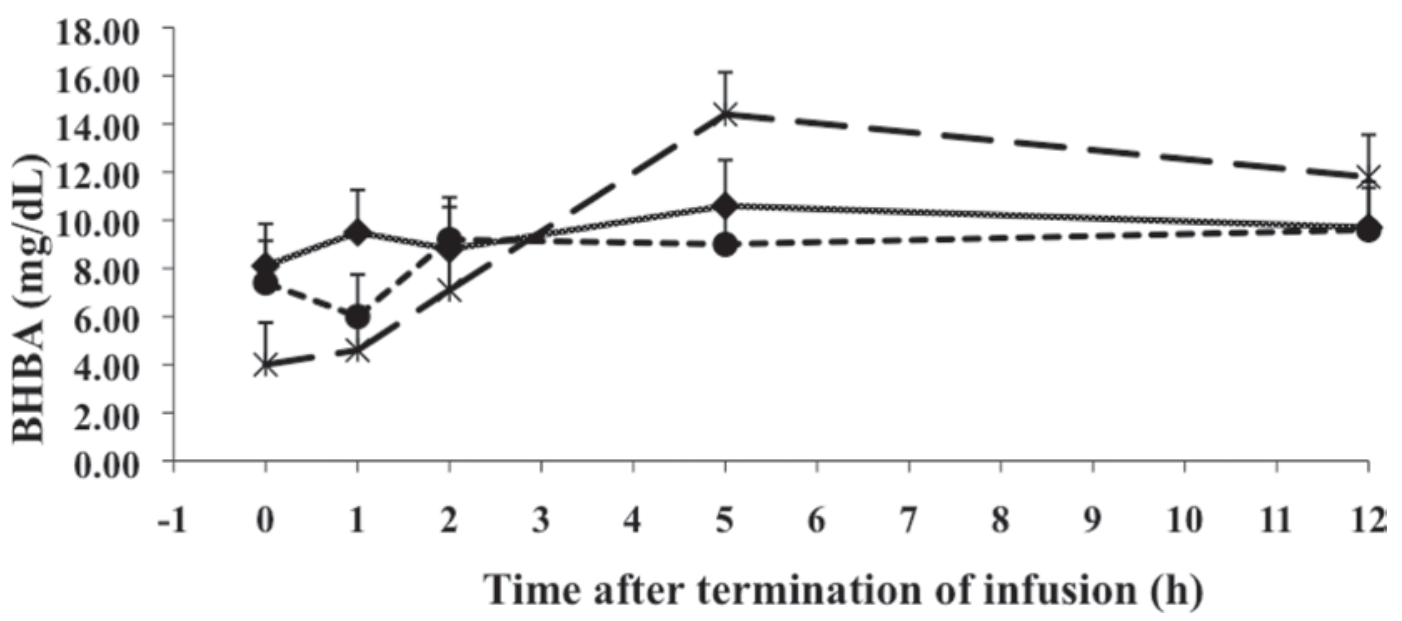

Figure 9. Experiment 1: plasma BHBA concentration after termination of nicotinic acid infusion at a rate of $0(\bullet$, solid line), $1.0(\bullet$, dotted line), or $3.0(\times$, dashed line $) \mathrm{mg} / \mathrm{h}$ per kilogram of BW. Significant effects: time $(P<0.001)$ and treatment $\times$ time $(P=0.01)$.

Because free niacin was fed in those trials, the lack of a treatment effect on BHBA was probably related to extensive ruminal degradation of NA.

\section{Experiment 2}

During periods 1 and 4 , the cows receiving $3 \mathrm{mg}$ of $\mathrm{NA} / \mathrm{h}$ per kilogram of BW had to be killed after $72 \mathrm{~h}$ of continuous infusion. A supplementary animal was included in the experiment after period 1 to substitute for the lost animal. After the second incidence during period 4, it was assumed that NA toxicity was the cause. However, at necropsy, both cows were diagnosed with Clostridium spp.; the exact cause of death is unknown. In contrast, no negative effects were perceptible when partially feed-restricted lactating cows received an identical infusion rate of NA $(3 \mathrm{mg} / \mathrm{kg}$ of BW per hour) for $74 \mathrm{~h}$ (Pires et al., 2009). In humans, niacin used in pharmacological doses has been associated with multiple adverse effects that include gastrointestinal upset, skin flushing, itching, hepatic dysfunction, metabolic acidosis, and hyperglycemia (McKenney et al., 1994; Mittal et al., 2007). Additionally, more severe liver toxicity and even fulminant hepatic failure have also been reported after ingestion of sustained-release NA formulations (Mullin et al., 1989).

Body weight $(747 \pm 24 \mathrm{~kg})$ and BCS $(3.5 \pm 0.2$; mean $\pm \mathrm{SD}$ ) were not affected by period. Lack of differences indicates that feed deprivation was not too severe, or that sufficient time was allowed between periods, or both.

Results from experiment 1 indicated that hourly abomasal infusions of $3 \mathrm{mg}$ of $\mathrm{NA} / \mathrm{h}$ per kilogram of BW had an antilipolytic effect. However, after the first dose was administered, a rebound in plasma NEFA concentration was observed, presumably during declining NA concentration in blood. Evidence was also present toward the end of the $12 \mathrm{~h}$ of NA infusions that plasma NEFA may have started to decline for some of the lower dose treatments. Therefore, a second study was conducted to determine whether the rebound effect could be avoided if NA was continuously infused into the abomasum and if the antilipolytic effect could be observed when lower doses were infused for a longer period of time.

In the second experiment the same dosage rates were used as in experiment 1 except the $0.25 \mathrm{mg}$ of $\mathrm{NA} / \mathrm{h}$ per kilogram of BW treatment was replaced by ruminal infusion of a commercially available ruminally protected form of NA at the rate of $0.5 \mathrm{mg} / \mathrm{h}$ per kilogram of BW. Comparison of this treatment with abomasal infusion of free NA at the rate of $0.5 \mathrm{mg} / \mathrm{h}$ per kilogram of BW allowed for an evaluation of whether NA in the commercial product was indeed protected in the rumen and available for absorption in the small intestine. The ruminal infusion of protected NA was initiated 2 $\mathrm{d}$ before abomasal infusions in an attempt to increase ruminal concentrations of NA and reach a more steady delivery of NA to the abomasum.

Treatment $(P<0.01)$, time $(P<0.001)$, and treatment by time $(P=0.02)$ effects were observed on plasma NEFA concentration (Figure 10). Plasma NEFA concentration started at approximately $70 \mu \mathrm{Eq} / \mathrm{L}$ for all the doses infused and resulted in 509, 587, 442, 850 , and $108 \mu \mathrm{Eq} / \mathrm{L}$ for cows that received 0, 0.5 (protected), 0.5 (free), 1 , and $3 \mathrm{mg}$ of $\mathrm{NA} / \mathrm{h}$ per kilogram of BW, respectively, at $108 \mathrm{~h}$ of continuous infusion of NA. Mean plasma NEFA concentration during $108 \mathrm{~h}$ of NA infusion was $457,493,389,634$, and $319 \mu \mathrm{Eq} / \mathrm{L}$ for cows that received $0,0.5$ (free), 0.5 (protected), 1 , and 


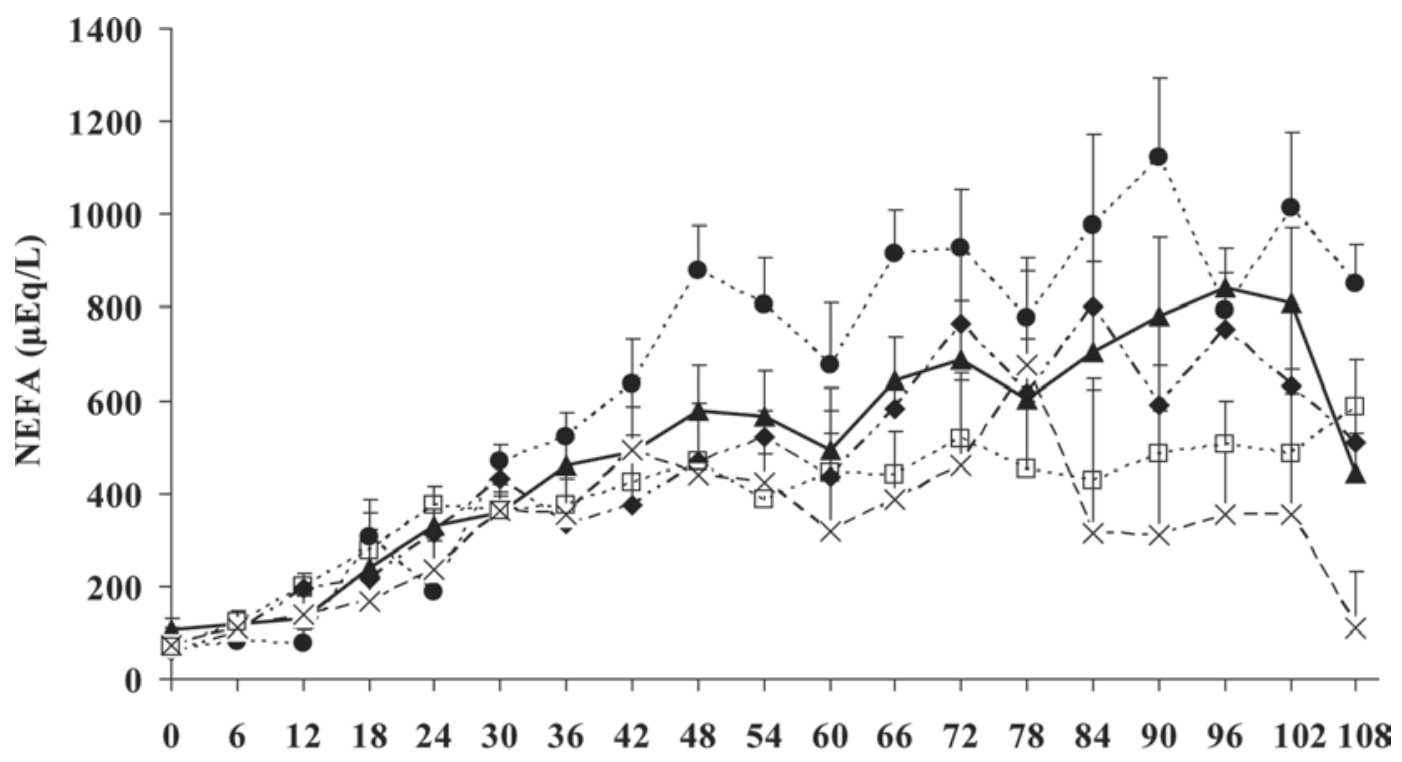

Infusion time (h)

Figure 10. Experiment 2: plasma NEFA concentration during abomasal infusions of nicotinic acid (NA) at a rate of 0 ( $\bullet$ dashed-dotted line), $0.5(\mathbf{\Lambda}$, solid line), $1.0(\bullet$, dotted line), or $3.0(\times$, dashed line) $\mathrm{mg}$ of free NA/h per kilogram of BW or ruminal infusion of $0.5 \mathrm{mg}(\square$, dotted line) of ruminally protected NA (NiaShure, Balchem Corp., New Hampton, NY)/h per kilogram of BW. Abomasal infusions of nicotinic acid started at $0 \mathrm{~h}$ of feed restriction and were administered continuously for $108 \mathrm{~h}$. Ruminal infusion started $48 \mathrm{~h}$ before feed restriction and was administered every $6 \mathrm{~h}$ for $156 \mathrm{~h}$. Significant effects: treatment $(P<0.001)$, time $(P<0.001)$, and treatment $\times$ time $(P<0.01)$.

$3 \mathrm{mg}$ of NA/h per kilogram of BW, respectively (Figure 11). Cows infused with $3 \mathrm{mg}$ of NA/h per kilogram of BW had lower plasma NEFA $(P \leq 0.01)$ than cows on other treatments. Cows receiving $1 \mathrm{mg}$ of $\mathrm{NA} / \mathrm{h}$ per kilogram of BW had significantly higher plasma NEFA than cows receiving $0.5 \mathrm{mg}$ (protected) of $\mathrm{NA} / \mathrm{h}$ per kilogram of BW $(P=0.03)$. Additionally, cows receiving $0.5 \mathrm{mg}$ (protected) of $\mathrm{NA} / \mathrm{h}$ per kilogram of $\mathrm{BW}$ had higher levels $(P=0.01)$ of plasma NEFA than cows supplemented with $3 \mathrm{mg}$ of $\mathrm{NA} / \mathrm{h}$ per kilogram of BW. We would have expected a dose-dependent decrease in plasma NEFA concentration to abomasal infusions of NA, but this did not occur. The reason for this is not obvious. Likewise, we expected $0.5 \mathrm{mg}$ of free $\mathrm{NA} / \mathrm{h}$ per kilogram of BW delivered to the abomasum to be more effective than $0.5 \mathrm{mg}$ of protected NA/h per kilogram of BW administered into the rumen in decreasing plasma NEFA. It was hypothesized that protected NA would not be $100 \%$ protected from ruminal degradation and would not be $100 \%$ absorbed in the small intestine. The only reasonable explanation for why protected NA was more effective is that its administration started $2 \mathrm{~d}$ earlier than other treatments.

After termination of NA infusion, significant treatment and time $(P<0.001)$ effects were observed and a trend $(P=0.08)$ was found for treatment by time interaction (Figure 12). Plasma NEFA concentrations were $524,893,494,1,383$, and $1,090 \pm 108 \mu \mathrm{Eq} / \mathrm{L}$ for
0, 0.5 (free), 0.5 (protected), 1 , and $3 \mathrm{mg}$ of $\mathrm{NA} / \mathrm{h}$ per kilogram of $\mathrm{BW}$, respectively (treatment effect; $P<0.001$ ) during the $12 \mathrm{~h}$ following termination of infusion. An increase in plasma NEFA concentration was observed for cows receiving 1 and $3 \mathrm{mg}$ of $\mathrm{NA} / \mathrm{h}$

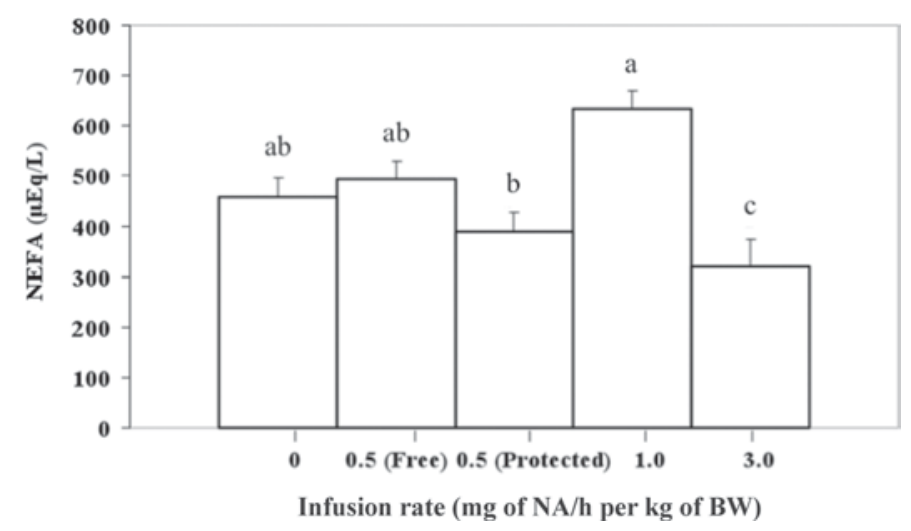

Figure 11. Experiment 2: mean plasma NEFA concentration during abomasal infusion of nicotinic acid (NA) at a rate of $0,0.5,1.0$, or $3.0 \mathrm{mg}$ of free $\mathrm{NA} / \mathrm{h}$ per kilogram of $\mathrm{BW}$ or ruminal infusion of $0.5 \mathrm{mg}$ of ruminally protected NA (NiaShure, Balchem Corp., New Hampton, NY)/h per kilogram of BW in feed-restricted Holstein cows. Abomasal infusions of nicotinic acid started at $0 \mathrm{~h}$ of feed restriction and were administered continuously for $108 \mathrm{~h}$. Ruminal infusion started $48 \mathrm{~h}$ before feed restriction and was administered every $6 \mathrm{~h}$ for 156 h. Significant effect: treatment $(P<0.001)$. Bars with different letters are significantly different $(P<0.05)$. 


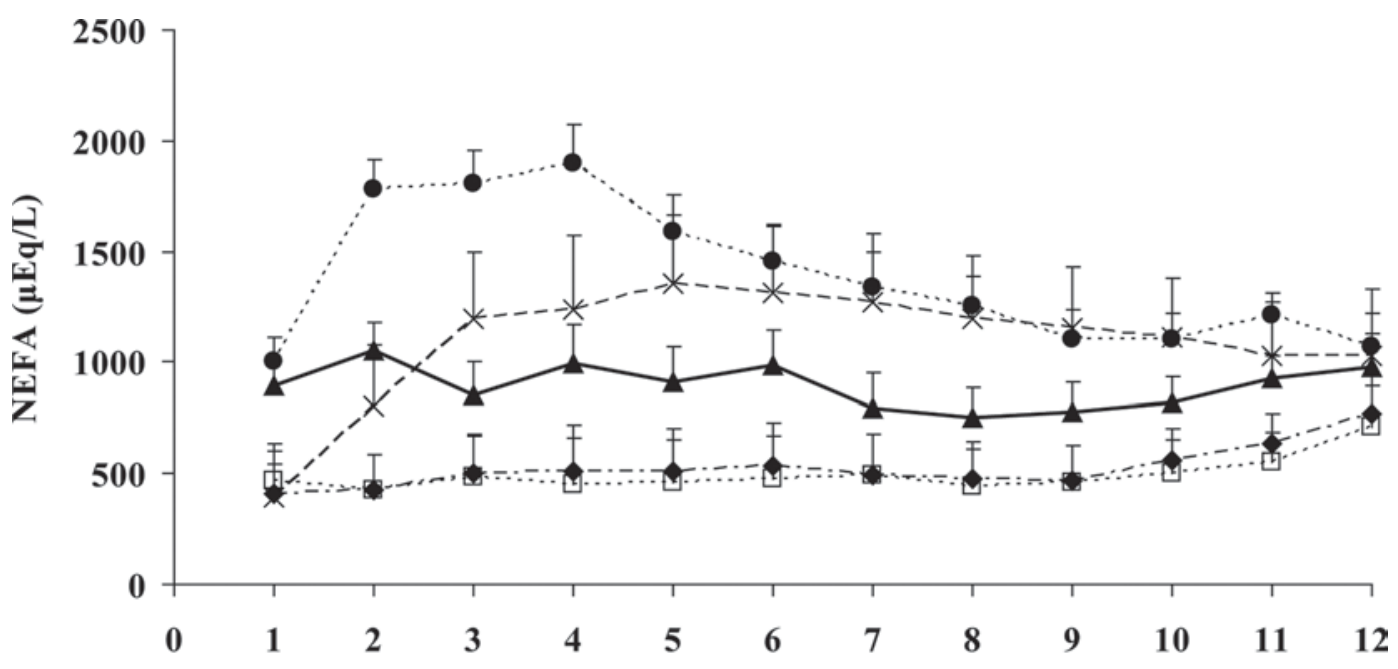

Time after termination of infusion (h)

Figure 12. Experiment 2: plasma NEFA concentration after termination of nicotinic acid (NA) infusion at a rate of 0 ( $\bullet$, dashed-dotted line), 0.5 ( $\mathbf{\Lambda}$, solid line), $1.0(\bullet$, dotted line), or $3.0(\times$, dashed line) $\mathrm{mg}$ of free NA/h per kilogram of BW or ruminal infusion of $0.5 \mathrm{mg}$ ( $\square$, dotted line) of ruminally protected NA (NiaShure, Balchem Corp., New Hampton, NY)/h per kilogram of BW in feed-restricted Holstein cows. After termination of infusion, blood was collected for 12 consecutive hours. Significant effects or trends: treatment $(P<0.001)$, time $(P<0.001)$, and treatment $\times$ time $(P=0.08)$.

per kilogram of BW compared with the other treatments $(P<0.05)$. Plasma NEFA concentration was approximately $1,900 \mu \mathrm{Eq} / \mathrm{L}$ at $4 \mathrm{~h}$ after termination of infusion for cows receiving $1 \mathrm{mg}$ of $\mathrm{NA} / \mathrm{h}$ per kilogram of $\mathrm{BW}$ and $1,360 \mu \mathrm{Eq} / \mathrm{L}$ at $5 \mathrm{~h}$ after termination of infusion for cows receiving $3 \mathrm{mg}$ of $\mathrm{NA} / \mathrm{h}$ per kilogram of BW. The rebound observed with $3 \mathrm{mg}$ of NA/h per kilogram of BW was probably related to its ability to reduce plasma NEFA concentration during the 108-h infusion (Figure 10). However, the rebound associated with $1 \mathrm{mg}$ of NA/h per kilogram of $\mathrm{BW}$ was not anticipated because this dose did not lower plasma NEFA concentration. A dose of NA that can suppress NEFA in nongestating, nonlactating cows without a rebound effect was not identified in this experiment or experiment 1. In contrast, Morey et al. (2009) fed 0 or $24 \mathrm{~g}$ of $\mathrm{NA} / \mathrm{d}$ in a protected form to dairy cattle from $21 \mathrm{~d}$ before calving to $21 \mathrm{~d}$ postpartum and observed that NA suppressed plasma NEFA concentration at calving but did not induce a rebound when treatment was terminated.

\section{CONCLUSIONS}

Previous research from our group indicated that abomasal infusion of NA is capable of reducing plasma NEFA in cows experiencing negative energy balance, presumably by inhibiting adipose lipolysis. Reduction of plasma NEFA may be a management tool that would prevent lipid-related metabolic disorders such as fatty liver and ketosis in dairy cattle. However, the lowest dose of NA used in previous studies appeared to cause maximal suppression of lipolysis, and after termination of infusion, plasma NEFA increased to 2 to 3 -fold greater than before initiation of infusion. For NA to be an effective management tool to prevent metabolic disorders, it would be desirable to identify a dose of NA that would suppress lipolysis yet avoid the rebound in plasma NEFA after termination of treatment. Results from the current studies showed that the highest dose (3 mg of NA/h per kilogram of BW, one-half the dose used in previous studies), delivered either as hourly doses for $12 \mathrm{~h}$ or as a continuous infusion for $108 \mathrm{~h}$, could suppress plasma NEFA in nongestating, nonlactating Holstein cows, but the rebound of plasma NEFA was not avoided. Evidence was found that the high dose was toxic after $72 \mathrm{~h}$ of infusion. The next highest dose, $1 \mathrm{mg}$ of NA/h per kilogram of BW delivered either as hourly doses for $12 \mathrm{~h}$ or as a continuous infusion for $108 \mathrm{~h}$, was not able to suppress NEFA. In experiment 2 (continuous $108 \mathrm{~h}$ infusion), this dose did result in a dramatic increase in plasma NEFA following termination of infusion. We conclude that it is unlikely that a dose of NA exists that can suppress NEFA in nongestating, nonlactating cows without the rebound effect.

\section{ACKNOWLEDGMENTS}

The authors thank Balchem Corporation (New Hampton, NY) for financial support of this research. 
Appreciation is extended to the staff at the Dairy Cattle Instruction and Research Center (University of Wisconsin, Madison) for animal care and to University of Wisconsin-Madison Department of Dairy Science students and staff for help during sample collection and processing.

\section{REFERENCES}

Bauman, D. E., and W. B. Currie. 1980. Partitioning of nutrients during pregnancy and lactation: A review of mechanisms involving homeostasis and homeorhesis. J. Dairy Sci. 63:1514-1529.

Campbell, J. M., M. R. Murphy, R. A. Christensen, and T. R. Overton. 1994. Kinetics of niacin supplements in lactating dairy cows. J. Dairy Sci. 77:566-575.

Gibbard, S., and P. J. Watkins. 1968. A micro-method for the enzymatic determination of $\mathrm{D}$ - $\beta$-hydroxybutyrate and acetoacetate. Clin. Chim. Acta 19:511-521.

Gressley, T. F., S. M. Reynal, J. J. O. Colmenero, G. A. Broderick, and L. E. Armentano. 2006. Technical note: Development of a tool to insert abomasal infusion lines into dairy cows. J. Dairy Sci. 89:3965-3967.

Grummer, R. R. 1993. Etiology of lipid-related metabolic disorders in periparturient dairy cows. J. Dairy Sci. 76:3882-3896.

Jaster, E. H., D. F. Bell, and T. A. McPherron. 1983. Nicotinic acid and serum metabolite concentrations of lactating dairy cows fed supplemental niacin. J. Dairy Sci. 66:1039-1045.

Karkalas, J. J. 1985. An improved enzymatic method for the determination of native and modified starch. J. Sci. Food Agric. $36: 1019-1027$

McKenney, J. M., J. D. Proctor, S. Harris, and V. M. Chinchili. 1994 A comparison of the efficacy and toxic effects of sustained- vs. immediate-release niacin in hypercholesterolemic patients. J. Am. Med. Assoc. 271:672-677.

Mittal, M. K., T. Florin, J. Perrone, J. H. Delgado, and K. C. Osterhoudt. 2007. Toxicity from the use of niacin to beat urine drug screening. Ann. Emerg. Med. 50:587-590.

Morey, S. D., B. J. Bradford, L. K. Mamedova, and D. E. Anderson. 2009. Effects of encapsulated niacin on metabolism and production of periparturient dairy cows. J. Dairy Sci. 92(E-Suppl. 1):519. (Abstr.)

Mullin, G. E., J. K. Greenson, and N. C. Mitchell. 1989. Fulminant hepatic failure after ingestion of sustained-release nicotinic acid. Ann. Intern. Med. 111:253-255.

NRC. 2001. Nutrient Requirements of Dairy Cattle. 7th rev. ed. Natl. Acad. Press, Washington, DC.
Nye, E. R., and H. Buchanan. 1969. Short-term effect of nicotinic acid on plasma level and turnover of free fatty acids in sheep and man. J. Lipid Res. 10:193-196.

Pires, J. A. A., C. L. Girard, and R. R. Grummer. 2008. Plasma concentration of nicotinic acid and derivatives in response to abomasal infusions of nicotinic acid. J. Dairy Sci. 91(E-Suppl. 1):483. (Abstr.)

Pires, J. A. A., and R. R. Grummer. 2007. The use of nicotinic acid to induce sustained low plasma nonesterified fatty acids in feedrestricted Holstein cows. J. Dairy Sci. 90:3725-3732.

Pires, J. A. A., J. B. Pescara, and R. R. Grummer. 2007. Reduction of plasma NEFA concentration by nicotinic acid enhances the response to insulin in feed-restricted Holstein cows. J. Dairy Sci. 90:4635-4642

Pires, J. A. A., L. F. Stumpf, I. D. Soutullo, J. B. Pescara, S. E. Stebulis, and R. R. Grummer. 2009. Effects of abomasal infusion of nicotinic acid on responses to glucose and $\beta$-agonist challenges in partially feed-restricted lactating cows. Pages 638-639 in Digestion, Metabolism, and Effects of Nutrition on Reproduction and Welfare. Proc. XIth Int. Symp. Ruminant Physiology, ClermontFerrand, France. Y. Chilliard, F. Glasser, Y. Faulconnier, F. Bocquier, and I. Veissier, ed. Wageningen Acad. Publ., Wageningen, the Netherlands.

SAS Institute. 2004. SAS/Stat 9.1 User's Guide. SAS Institute Inc. Cary, NC.

Schwab, E. C., D. Z. Caraviello, and R. D. Shaver. 2005. A metaanalysis of lactation responses to supplemental dietary niacin in dairy cows. Prof. Anim. Sci. 21:239-247.

Thornton, J. H., and L. H. Schultz. 1980. Effects of administration of nicotinic acid on glucose, insulin, and glucose tolerance in ruminants. J. Dairy Sci. 63:262-268.

Vazquez-Añon, M., S. Bertics, M. Luck, R. R. Grummer, and J. Pinheiro. 1994. Peripartum liver triglyceride and plasma metabolites in dairy cows. J. Dairy Sci. 77:1521-1528.

Waterman, R., and L. H. Schultz. 1972. Nicotinic acid loading of normal cows: Effects on blood metabolites and excretory form. J. Dairy Sci. 55:1511-1513.

Waterman, R., and L. H. Schultz. 1973. 1-Carbon 14-labeled palmitic acid metabolism in fasted, lactating goats following nicotinic acid administration. J. Dairy Sci. 56:1569-1574.

Waterman, R., J. W. Schwalm, and L. H. Schultz. 1972. Nicotinic acid treatment of bovine ketosis. I. Effects on circulatory metabolites and interrelationships. J. Dairy Sci. 55:1447-1453.

Zinn, R. A., F. N. Owens, R. L. Stuart, J. R. Dunbar, and B. B. Norman. 1987. B-vitamin supplementation of diets for feedlot calves. J. Anim. Sci. 65:267-277. 